Conclusions The main reasons for changing from HAART to twodrug regimens were drug resistance tests and simplification of the antiretroviral treatment. Taking into account the limitation of the study due to its short follow-up and the limited number of patients, we can say that in our study, the change to a treatment with two active antiretroviral drugs seems to be at least as effective as the three-drug HAART regimen.

Abstract DGI-015 Table 1

\begin{tabular}{|c|c|c|c|c|}
\hline & $\begin{array}{l}\text { VPL at start } \\
\text { of two-drug } \\
\text { regimen }\end{array}$ & $\begin{array}{l}\text { CD4 at start } \\
\text { of two-drug } \\
\text { regimen }\end{array}$ & $\begin{array}{l}\text { VPL } \\
24 \text { weeks }\end{array}$ & $\begin{array}{l}\text { CD4 } \\
24 \text { weeks }\end{array}$ \\
\hline $\begin{array}{l}\text { Change due to drug } \\
\text { resistance test } \\
12 \text { patients }\end{array}$ & $\begin{array}{l}2 \text { patients VLS } \\
10 \text { patients Medium } \\
\text { VPL } 5449 \mathrm{c} / \mathrm{ml}\end{array}$ & $433 / \mathrm{ml}$ & $\begin{array}{l}9 \text { patients VLS } \\
3 \text { patients Medium } \\
\text { VPL } 44388 \mathrm{c} / \mathrm{ml}\end{array}$ & $461 / \mathrm{ml}$ \\
\hline $\begin{array}{l}\text { Change due to side } \\
\text { effects } \\
6 \text { patients }\end{array}$ & $\begin{array}{l}4 \text { patients VLS } \\
2 \text { patients Medium } \\
\text { VPL } 142515 \mathrm{c} / \mathrm{ml}\end{array}$ & $306 / \mathrm{ml}$ & 6 patients VLS & $336 / \mathrm{ml}$ \\
\hline $\begin{array}{l}\text { Change for } \\
\text { simplification } \\
12 \text { patients }\end{array}$ & 12 patients VLS & $589 / \mathrm{ml}$ & 12 patients VLS & $427 / \mathrm{ml}$ \\
\hline
\end{tabular}

No conflict of interest.

\section{DGI-016 ASSESSMENT OF TOCILIZUMAB PRESCRIPTIONS AT A UNIVERSITY HOSPITAL}

doi:10.1136/ejhpharm-2013-000276.282

${ }^{1} \mathrm{~F}$ Bringer, ${ }^{1} \mathrm{M}$ Villiet, ${ }^{1} \mathrm{C}$ Breuker, ${ }^{1} \mathrm{~N}$ Gastaut, ${ }^{2} \mathrm{G}$ Mercier, ${ }^{3 P}$ Aubas, ' $\mathrm{S}$ Hansel-Esteller. ${ }^{1} \mathrm{CHRU}$ Lapeyronie, Pharmacie, 34295 Montpellier, France; ${ }^{2} \mathrm{CHRU}$ Lapeyronie, EA714 ERFI-Université Montpellier 1, 34295 Montpellier, France; ${ }^{3} \mathrm{CHRU}$ Lapeyronie Département d'Information Médicale, 34295 Montpellier, France

Background Tocilizumab (TCZ) is an anti-IL-6 agent given as second-line biotherapy in the treatment of rheumatoid arthritis (RA). Guidelines for the prescription of TCZ indicate that it must be administered after anti-TNF- $\alpha$ failure at the University Hospital of Montpellier (UHM).

Purpose To assess the prescriptions for TCZ and cheque them against the existing guidelines since an increasing number of patients are treated at the UHM.

Materials and Methods The study was conducted over a period of 20 months, from January 2010 (marketing of TCZ) to July 2011. Patients treated with TCZ were identified thanks to the hospital information database. Data collected were: indications, previous treatment, number of anti-TNF- $\alpha$ drugs used before TCZ, association with conventional treatment, and biotherapy implemented if TCZ fails.

Results 149 patients were treated with TCZ: RA 93.4\%, juvenile idiopathic arthritis $3.7 \%$, Still's disease and ankylosing spondylitis $2.9 \%$ (off-label).

All patients had previously been treated with methotrexate (MTX).

TCZ was administered after failure of anti-TNF- $\alpha$ in $79.2 \%$ of the cases. $13.4 \%$ received TCZ as first-line biotherapy.

For $59.1 \%$ of patients, TCZ was associated with the conventional treatment. $62.6 \%$ were treated with MTX.

We evaluated the effectiveness of TCZ in 88 patients (patients who had not started their treatment in clinical trials in the last 6 months of the study): the treatment was successful for 67 of them (76.1\%). TCZ was not effective in $23.9 \%$ with a mean treatment duration of 7.1 months. For these patients, TCZ was switched to abatacept (anti-CTLA4) 47.6\%, anti-TNF- $\alpha 33.3 \%$ or rituximab (anti-CD20) $19.1 \%$.

Conclusions TCZ is an active molecule in the treatment of RA. Our guidelines are not always respected since TCZ was used as first-line biotherapy in $13.4 \%$ of patients. Further evaluation of this early use is needed to understand the practise of the prescribers.

No conflict of interest.

\section{DGI-017 BEVACIZUMAB PLUS IRINOTECAN IN MALIGNANT GLIOMAS}

doi:10.1136/ejhpharm-2013-000276.283

M Rodriguez Rodriguez, EY Romero Ventosa, S Gonzalez Costas, A Mucientes Molina, L Esarte López, N Lago Rivero, M Gayoso Rey, G Piñeiro Corrales. Hospital Xeral-Cies (CHUVI), Pharmacy, Vigo, Spain

Background Malignant gliomas (MG) comprise the most common types of primary central nervous system tumours.

Purpose An observational study to evaluate the efficacy and safety of bevacizumab plus irinotecan used off-label in recurrent malignant gliomas.

Materials and Methods Pharmacy records were reviewed to identify patients with histologically proven $\mathrm{MG}$ who had been treated with bevacizumab plus irinotecan as second- or third-line chemotherapy. Eligible patients: radiological evidence of tumour recurrence or progression prior to initiation of chemotherapy and STUPP regimen as first line. Patients were treated with IV bevacizumab $(10 \mathrm{mg} / \mathrm{kg})$ on days 1,15 and 29 every 6 weeks and IV irinotecan $\left(340 \mathrm{mg} / \mathrm{m}^{2}\right.$ if concomitant enzyme-inducing antiepileptic drugs (EIAEDs) or $125 \mathrm{mg} / \mathrm{m}^{2}$ if no EIAEDs) on days 1,15 and 29 every 6 weeks. Treatment was continued until disease progression or unacceptable toxicity. Tumours were evaluated by brain MRIs. Response to treatment was assessed at baseline and every 3 cycles or whenever progression was clinically suspected. The Macdonald criteria were used to evaluate the response. Toxicity was assessed before each cycle by medical history, haematology and biochemistry. Adverse events were graded according to NCI-CTCAEv4. Antiepileptics were administered as medically indicated.

Results Seven patients ( 5 men, 2 women) were evaluated. Mean age was 52.4 years and glioblastoma multiforme (GBM) was the major histotype (71\%). $71.4 \%$ of patients had had a total resection as primary surgery and $14.3 \%$ of patients had undergone second surgery at disease recurrence. The median number of cycles administered was 4 . Overall activity comprised 3 partial responses (42.86\%); and 1 (14.28\%) disease stabilisation for a Disease Control Rate of $57.14 \%$. Three patients (42.86\%) experienced disease progression. The median progression-free survival was 8.2 months $(95 \%$ confidence interval (CI): 5.4-10.9) and the median overall survival was 11.8 months (95\% CI: 6.1-17.5). No central nervous system haemorrhages occurred, but one patient developed deep venous thromboses.

Conclusions The combination of bevacizumab and irinotecan seems to run as an alternative and active regimen for recurrent MG with acceptable toxicity but it is necessary to expand the study population to draw definitive conclusions.

No conflict of interest.

\section{DGI-018 BUDGET IMPACT ANALYSIS ON NEW 3-YEAR IMATINIB ADJUVANT TREATMENT FOR PATIENTS WITH OPERABLE GIST AT HIGH RISK OF RECURRENCE}

doi:10.1136/ejhpharm-2013-000276.284

'V Manescotto, ${ }^{1 S}$ Osella, ${ }^{2} \mathrm{E}$ Cagliero, ${ }^{3} \mathrm{~A}$ Leggeri, ${ }^{4} \mathrm{~L}$ Cattel, ${ }^{5} \mathrm{~A}$ Comandone. ${ }^{1}$ University of Turin, School of specialisation in hospital pharmacy, Turin, Italy; ${ }^{2}$ ASL CN1, Territorial Pharmacy, Cuneo, Italy; ${ }^{3}$ Director San Giovanni Bosco Hospital, Hospital Pharmacy, Turin, Italy; ${ }^{4}$ University of Turin, Director School of specialisation in hospital pharmacy, Turin, Italy; ${ }^{5}$ Gradenigo Hospital, Director UOA Oncology, Turin, Italy

Background The results of Phase III of the (SSG)XVIII/AIO clinical study on imatinib (IM) in adjuvant treatment of GIST show that, after five years of follow up, 3 years of treatment lead to $66 \%$ 
of patients free of recurrence compared to $48 \%$ who received IM for only one year, with a $18 \%$ relative risk reduction. This result will determine the new standard of 3 years of adjuvant IM treatment in GIST patients at high risk of recurrence.

Purpose To analyse the budget impact on Piedmont Region, over 3 years, after the approval by the Italian National Regulatory Agency of 3 years' adjuvant treatment in high-risk GIST.

Materials and Methods The analysis was performed considering the estimated incidence of 60 new cases of GIST in Piedmont: 28 patients are at very low/low risk of relapse and don't need IM; 8 patients are at intermediate risk of recurrence and should receive IM only for 1 year; 12 patients are at very high/high risk and are treated with adjuvant IM for 3 years; 12 patients are metastatic at diagnosis and require lifelong treatment (5-13 years). The price of IM considered in this study was fixed (6-2011) in the regional competition in Piedmont (at 16.7305€/100 mg capsule).

Results The annual expenditure for 12 very high/high risk patients is $293,118.6 €$ which adds up to a total of $879,355.08 €$ in 3 years. Given the stability of GIST incidence ( 5 cases $/ 1,000,000$ people) and $30 \%$ drop off from treatment for intolerance as reported in the SSG/ AIO study, the result of our study was: in the first year 12 patients were treated at a total cost of $293,118.36 €$. The second year for 20 patients ( 8 from the first year +12 new) the expenditure was $488,530.6 €(+66.66 \%)$. The third year there were 27 patients (7 from the first year, 8 from the second year, 12 new) and a total amount of $659,516.31 €$ ( $+35 \%$ compared to the second year). The total expenditure on very high/high risk patients at the end of 3 years of observational study was $1,441,165.27 €$ and the overall incremental cost was $+125 \%$.

Conclusions The cost of health interventions in rare tumours should be carefully planned with a specific cancer and pharmacological registry. The availability of comprehensive databases or regional registries of these treatments would allow a more accurate analysis that takes into account both the cost of medicines and ambulatory treatment and follow-up cost. Even though data on current costs are alarming it is important to consider that in 2014 IM will lose the Novartis patent and costs will drop about $30-40 \%$.

No conflict of interest.

\section{DGI-019 CISPLATIN DESENSITISATION PROTOCOL}

doi:10.1136/ejhpharm-2013-000276.285

${ }^{1} \mathrm{C}$ Sangrador-Pelluz, ${ }^{2} \mathrm{M}$ Martinez-García, 'MD Pérez-Serrano-Lainosa, 'R OlivaresPallerols, 'JP Navarro-Ferrando, 'E Soler-Company. 'Hospital Arnau de Vilanova, Pharmacy, Valencia, Spain; ${ }^{2 H o s p i t a l}$ Arnau de Vilanova, Allergy, Valencia, Spain

Background Hypersensitivity reactions are adverse events that represent a challenge, because in some cases there isn't an alternative treatment. Consequently, the only option is to desensitise the patient.

Purpose To describe a cisplatin desensitisation protocol (CDP) in a patient with a previous anaphylactic reaction.

Materials and Methods Male diagnosed with lung cancer, who started chemotherapy with cisplatin $75 \mathrm{mg} / \mathrm{m}^{2}$ and oral vinorelbine $60 \mathrm{mg} / \mathrm{m}^{2}$. During the cisplatin infusion, he suffered an anaphylactic reaction, so it was decided to perform skin tests, to confirm the possible association with the cytostatic.

Due to the cross-reactivity between platinum salts, these tests were performed with all similar substances. Stock solutions used: cisplatin $1 \mathrm{mg} / \mathrm{ml}$, carboplatin $5 \mathrm{mg} / \mathrm{ml}$ and oxaliplatin $10 \mathrm{mg} / \mathrm{ml}$. Dilutions prepared for intradermal administration: 1/10000, 1/1000, $1 / 100$ and $1 / 10$.

Results Cisplatin skin tests were positive for the stock solution and negative for the other dilutions. All the other platinum salts were negative, so we developed a protocol for administering the next cycle of cisplatin.

The CDP consisted of 12 stages in which to administer the total dose $(140 \mathrm{mg})$. Three solutions $(250 \mathrm{ml})$ were prepared with dilutions $1 / 100,1 / 10$ and $1 / 1$. The $1 / 100$ solution $(0.0056 \mathrm{mg} / \mathrm{ml})$ was administered at $9.25 \mathrm{ml}$ in 1 hour in 4 stages (administration rate increments every 15 minutes: $2 \mathrm{ml} / \mathrm{h}, 5 \mathrm{ml} / \mathrm{h}, 10 \mathrm{ml} / \mathrm{h}$ and $20 \mathrm{ml} / \mathrm{h}$ ). The $1 / 10$ solution $(0.056 \mathrm{mg} / \mathrm{ml})$ was administered at $18.75 \mathrm{ml}$ in 1 hour in 4 steps (starting with $5 \mathrm{ml} / \mathrm{h}$ and doubling the rate every 15 minutes until $40 \mathrm{ml} / \mathrm{h})$. Solution $1 / 1(0.56 \mathrm{mg} / \mathrm{ml})$ was administered completely, starting with $10 \mathrm{ml} / \mathrm{h}$ and increasing every $15 \mathrm{~min}$ to 20,40 and $80 \mathrm{ml} / \mathrm{h}$, being the final perfusion rate. It was performed under medical supervision, taking in total 5 hours and 37 minutes. The patient didn't have any complications.

Conclusions In this patient, the CDP developed enabled the chemotherapy to be given safely. All this was possible by the interdisciplinary collaboration of allergy, oncology and pharmacy services.

No conflict of interest.

\section{DGI-020 COST AND EFFECTIVENESS OF TARGETED TREATMENT WITH CETUXIMAB OR BEVACIZUMAB AS MAINTENANCE TREATMENT IN PATIENTS WITH COLORECTAL CANCER}

doi:10.1136/ejhpharm-2013-000276.286

${ }^{1} \underline{G}$ Rizza, ${ }^{2} \mathrm{G}$ Bellavia, ${ }^{2} \mathrm{C}$ Scorsone, ${ }^{1} \mathrm{~V}$ Cascone. ${ }^{1} \mathrm{ASP}$ of Ragusa, Hospital Pharmacy RG 1 Distrect, Ragusa, Italy; ${ }^{2}$ ASP of Agrigento, Hospital Pharmacy AG 2 Distrect, Agrigento, Italy

Background The addition of targeted treatment to chemotherapy and first and second line treatment significantly improves patient outcomes, raising the response rate with an increase of resectability in patients with metastasis and improving the long-term survival, as demonstrated by several randomised clinical trials.

Purpose To evaluate the cost and effectiveness of treatment with bevacizumab or cetuximab in patients with metastatic colorectal cancer, in particular in maintenance treatment.

Materials and Methods A retrospective analysis was conducted in two Sicilian cancer centres, in patients treated between 01/01/2008 and 30/06/2012, to assess the median time to progression (TTP) and the corresponding cost of maintenance treatment with bevacizumab and cetuximab. Results were compared using the log-rank test.

Results Of 167 patients treated with bevacizumab plus chemotherapy, 41 (24.5\%) responded and continued with maintenance treatment: 36 patients on first-line treatment (TTP 412.5 days) and 5 patients on second-line treatment (TTP 314.7 days). Of 71 patients treated with cetuximab plus chemotherapy, 15 (21.1\%) responded and continued with maintenance treatment: 9 patients on first-line treatment (TTP 271.2 days), 6 patients on second-line treatment (TTP 366.5 days). Maintenance treatment showed an increase in TTP of 258.2 and 159.3 days on first-line treatment, 188.1 and 243 days on second-line treatment for bevacizumab and cetuximab, respectively. The additional cost of maintenance treatment with bevacizumab and cetuximab, for a standard $70 \mathrm{~kg}, 1.7 \mathrm{~m}^{2}$ patient is $€ 84 /$ day and $€ 118 /$ day for each day of progression-free survival, respectively.

Conclusions In patients responding to maintenance treatment, bevacizumab is more advantageous as TTP in first-line treatment gains about 100 days vs. cetuximab, while cetuximab is more advantageous as second-line treatment, with a gain of about 55 days in TTP vs. bevacizumab. From the economic analysis the most advantageous is bevacizumab, costing $€ 34 /$ day less than cetuximab. A study is in progress to consider the use of targeted treatment with different chemotherapy regimens.

No conflict of interest. 